\title{
Methionine Synthase Reductase-A66G and -C524T Single Nucleotide Polymorphisms and Prostate Cancer:ACase-Control Trial
}

\author{
Atefeh Basir*
}

\begin{abstract}
Purpose: Some variations in the sequence of methionine synthase reductase (MTRR) gene can increase the risk of various cancers such as prostate cancer. The aim of this study was to investigate the association between prostate cancer and the MTRR A66G and C524T gene single nucleotide polymorphisms (SNPs) using an in silico analysis. Methods: In this case-control study, 218 Iranian men, including 108 men with prostate cancer and 110 prostate cancer-free men, were enrolled. The MTRR A66G and C524T genotyping was performed by PCR-RFLP. Some of the bioinformatics tools were employed for the evaluation of polymorphism on the molecular aspects of the MTRR. Results: With regard to the MTRR A66G polymorphism, the genotype AG (OR: 0.85, 95\% CI: $0.47-1.54, p=0.6014)$, genotype GG (OR: $0.89,95 \%$ CI: $0.42-1.87, p=0.7512)$, and allele G (OR: $0.92,95 \%$ CI: 0.63-1.35, $p=0.6686)$ were not associated with prostate cancer risk. However, the data for C524T SNP showed that the genotype CT was associated with prostate cancer risk (OR: 1.92, 95\% CI: 1.06-3.47, p= 0.0308). Further, carriers of the allele T (OR: 1.80, 95\% CI: 1.04-3.13, $\mathrm{p}=0.0358$ ) were associated with high risk of prostate cancer. In addition, bioinformatics analysis revealed that C524T SNP could affect some molecular aspects of the protein structure, while having no effect on the mRNA structure. Conclusion: The MTRR C524T is a genetic risk factor for prostate cancer; however, the MTRR A66G is not suggested as a suitable biomarker for prostate cancer. To obtain more reliable results, further studies are recommended to use larger sample sizes and investigate the effects of environmental factors.
\end{abstract}

Keywords: Prostate cancer- MTRR gene- genetic polymorphism- PCR-RFLP

Asian Pac J Cancer Prev, 20 (5), 1445-1451

\section{Introduction}

Prostate cancer is one of the leading causes of cancer death in men (Jemal et al., 2011; Karimian et al., 2018; Mazoochi et al., 2018). Several factors, including environmental, race, lifestyle, and genetic factors may affect the prostate cancer risk (Muslumanoglu et al., 2009; Ingles et al., 1997; Ebrahimi et al., 2017; Noureddini et al., 2018). Folate pathway is essential for the maintenance of genome integrity (Donnelly, 2001; Fowler 2005; Karimian and Colagar, 2016), is involved in tumorigenicity, and plays an importance role in process of DNA repair and methylation (Kim et al., 2009).

Given that folate is crucial for biosynthesis of nucleotide and replication of DNA, and it is a source of methyl $(\mathrm{CH} 3)$ group, it is essential for repair and development of cell. Studies suggest that folate deficiency is associated with increase of tumorigenesis risk in early stages, while excessive intake of folic acid might give rise to growth of malignant cells (Ulrich and Potter, 2007a). In spite of confirming folate essential role in preserving genome integrity, the anti-cancer function of folate is not clarified yet. Recent studies have proposed that the timing of folate intake within the development of cancer may change the disease outcome (Ulrich and Potter, 2006). Folate intake before the presence of pre-neoplastic damage can inhibit tumor growth, while folate provision during establishment of primary damages seems to elevate tumor progression, suggesting the important role of folate function in synthesis of nucleotide. Rapidly proliferating tumor cells requires an elevated level of nucleotides; therefore, several malignancies up-regulate receptors of folate, and folate antagonists can be efficient in cancer therapy (Ulrich and Potter, 2007).

Since folate pathway is involved in the methylation of key proteins such as histones, homocysteine removal, and methylation of DNA and RNA therefore, failings in this pathway could cause DNA breaks, inopportune methylation, imperfect repair of DNA, and accumulation of homocysteine (Le et al., 2000; Duthie and Hawdon, 1998; Duthie et al., 2000). These changes can cause abnormality in methylation of DNA, and eventually 
can lead to genomic instability (Godmann et al., 2009). These defects in the metabolism of folate can be arisen due to following reasons: 1- defect in key genes in this pathway, and 2- a diet low in folate (Nikzad et al., 2015; Karimian and Hosseinzadeh Colagar, 2016). There are four key genes in the folate metabolizing pathway, namely methionine synthase (MTR), methylenetetrahydrofolate reductase (MTHFR), thymidylate synthase (TS), and methionine synthase reductase (MTRR). Genetic polymorphisms in these genes may increase the risk of different cancers (Suzuki et al., 2008). The MTRR is one of the chief enzymes in the folate metabolism, affecting homocysteine levels. Methionine synthase reductase can lead to reduction of MTR-cob (II) alamin to MTR-cob (I) alamin, and subsequently it can convert 5-methyltetrahydrofolate to tetrahydrofolate. Finally, the remethylation of homocysteine to methionine can be achieved following these changes (Olteanu and Banerjee, 2001; Silaste et al., 2001; Karimian and Hosseinzadeh Colagar, 2018).

The human MTRR is a housekeeping gene, and it is located on chromosom 5p15.2-p15.3 (Rai et al., 2012). The A66G (rs1801394) single nucleotide polymorphism (SNP) with ID no: is the most prevalent polymorphism in the MTRR gene, leading to substitution of isoleucine with methionine at position 22 (I22M) (Olteanu and Banerjee, 2001). The C524T (rs1532268) is another common SNP in the MTRR gene, which results in substitution of a serine to leucine at codon 175 (S175L) (Zeng et al., 2011). The aim of the current study was to study the association between prostate cancer and A66G and C524T single nucleotide polymorphisms (SNPs) in the MTRR gene using an in silico approach.

\section{Materials and Methods}

\section{Collection and analysis of blood samples}

Two hundred and eighteen participants (108 men with cancer of prostate and 110 prostate cancer-free men) with the same geographical origin were included in our case-control study. All participants were originally from Central Iran. Participants with prostate cancer were selected among those who referred to Shahid Beheshti Hospital between May 2015 and January 2017. They were diagnosed with prostate cancer using high levels of PSA serum $>2.5 \mathrm{ng} / \mathrm{ml}$ and based on histopathology results. Prostate cancer-free participants were chosen from persons who referred to the same hospital for routine check-up with PSA $<2.5 \mathrm{ng} / \mathrm{ml}$ and/or normal digital rectal examination. Since the MTRR gene polymorphisms are associated with some diseases such as cancers and male infertility, all participants were examined for these disorders. After obtaining signed informed consent, a $2 \mathrm{~mL}$ sample of blood was drawn from each participant. Blood sampled were kept in impregnated EDTANa2 tubes. All procedures were done according to the ethical standards of the responsible committee on human experimentation (institutional and national) and 1975 Helsinki Declaration.

\section{DNA isolation and primers}

We analyzed two single nucleotide polymorphisms in the MTRR gene. DNA was isolated from each blood sample using commercial DNA isolation kits which was mentioned in our previous studies (Talebi et al., 2018; Rafatmanesh et al., 2018). For designing the primer, the complete MTRR gene sequence was acquired from NCBI databank (no. NC_000005.10). The primers were designed by the Oligo $\overline{6}$ offline software (Molecular Biology Insights, Inc., West Cascade, CO, USA). The sense and anti-sense primer sequences sets used for amplification of fragments containing the MTRR-A66G and MTRR-C524T polymorphisms are presented in Table 1.

\section{PCR-RFLP}

The genotypes of both the MTRR A66G and MTRR C524T polymorphisms were detected by polymerase chain reaction-restriction fragment length polymorphism (PCR-RFLP). For amplification of the MTRR sequences, a PCR was done in $20 \mu \mathrm{L}$ overall volume comprising $10 \mu \mathrm{L}$ PCR master mix $2 \mathrm{X}, 0.35 \mathrm{mM}$ of each forward and reverse primers, and $30 \mathrm{ng}$ template DNA. The DNA amplification was done in an Eppendorf thermal cycler (Eppendorf AG, Hamburg, Germany) using a program which is presented in Table 1 . PCR reagents were purchased from CinnaGen Co. (Tehran, Iran).

PCR yields were checked on a $1 \%$ agarose gel. To detect the MTRR A66G genotypes, the amplified fragments were digested by NspI restriction enzyme (Fermentas Co., Lithuania), and to detect the MTRR C524T genotypes, the PCR products were treated by XhoI restriction endonuclease (Fermentas Co., Lithuania). Each digestion mixture contained $10 \mu$ l of the PCR product, $0.7 \mu \mathrm{l}$ of restriction enzyme, and $0.7 \mu \mathrm{l}$ buffer in $10 \mu$ l overall volume. The mixture was incubated at $37^{\circ} \mathrm{C}$ overnight. Then, digested enzymatic mixtures for A66G and C524T polymorphisms were electrophoresed in $8 \%$ polyacrylamide and $1 \%$ agarose gels, respectively.

\section{Bioinformatics tools}

A bioinformatics approach was employed to evaluate the subsequent molecular aspects of C524T SNP. For this purpose, the DNA sequence of the MTRR gene (with accession number AC010346.6) was obtained from the National Center for Biotechnology Information (NCBI; http://www.ncbi.nlm.nih.gov/). The coding sequence of the MTRR gene carrying both 524C and 524T alleles were translated to amino acid sequence by ExPASy server (http://web.expasy.org/ translate/) for subsequent applications. Physicochemical properties of translated sequence were evaluated by ProtParam server (http://web. expasy.org/protparam/). The effects of this substitution on function of the protein were assessed by SNAP (https:// rostlab.org/services/snap/) and PolyPhen-2 (http:// genetics.bwh.harvard .edu/pph2/) web servers. The effects of C524T SNP on the mRNA structure were assessed by RNAsnp web server (http://rth.dk/ resources/rnasnp/).

\section{Statistical analysis}

Deviation from Hardy-Weinberg equilibrium (HWE) criteria was estimated by utilizing a $\chi^{2}$ test. The strength of association between risk of prostate cancer and the MTRR 
A66G and MTRR C524T polymorphisms was assessed by calculating odds ratios (ORs) and 95\% confidence interval (CIs) through a binary logistic regression. A p-value< 0.05 was considered statistically significant. Statistical analyses were done in SPSS 19 (SSPS Inc., IBM Corp Armonk, NY, USA).

\section{Results}

\section{MTRR-A66G and MTRR-C524T genotyping}

The MTRR fragment containing A66G SNP with size of 118-bp was amplified by PCR. After gel electrophoresis of enzymatic mixtures, the genotype AA exhibited a fragment (118-bp) on $8 \%$ polyacrylamide gel, the genotype AG displayed three fragments (118-, 94-, and $24-\mathrm{bp}$ ) on $8 \%$ polyacrylamide gel; whereas, genotype GG exhibited two bands (94- and 24-bp) on 8\% polyacrylamide gel (Figure 1). Then, MTRR fragment covering C524T SNP with size of 575-bp was amplified by PCR. After electrophoresis of enzymatic mixtures, the genotype CC displayed two fragments (368- and 206-bp), the genotype CT displayed three fragments (575-, 368-, and 206-bp); whereas, genotype TT displayed a band (575-bp) on $1 \%$ agarose gel (Figure 2 ).

\section{Genetic association analysis}

The distribution of the MTRR genotypes for A66G and C524T SNPs was not deviated from Hardy-Weinberg equilibrium in both case and control groups. The frequencies of alleles and genotypes for the A66G in case and control groups are elaborated in Table 2. Our data showed that the genotype AG (with OR: $0.85,95 \%$ CI: 0.47-1.54, $\mathrm{p}=0.6014$ ), genotype GG (with OR: 0.89, 95\% CI: 0.42-1.87, $\mathrm{p}=0.7512$ ), and $\mathrm{G}$ allele (with OR: $0.92,95 \%$ CI: $0.63-1.35, p=0.6686)$ were not associated with prostate cancer risk. The frequencies of alleles and genotypes for the C524T SNP in both case and control groups are shown in Table 3. The data for C524T SNP showed that the genotype CT (with OR: 1.92, 95\% CI: 1.06-3.47, $\mathrm{p}=0.0308$ ) was associated with prostate cancer risk. In addition, carriers of the allele $\mathrm{T}$ (with OR: 1.80, 95\% CI: 1.04-3.13, $\mathrm{p}=0.0358$ ) were associated with high risk of prostate cancer. However, genotype TT (with OR: 1.54, 95\% CI: 0.71-3.34, $\mathrm{p}=0.2762$ ) and allele T (with OR: 1.38, 95\% CI: 0.94-2.03, $\mathrm{p}=0.1042$ ) were not associated with risk of prostate cancer.

\section{Effects of C524T substitution on the protein and $m R N A$}

According to Protparam server, C524T substitution marginally affected physical and chemical properties of the MTRR gene. The results of mentioned server are demonstrated in Table 4. Data from SNAP server revealed that C524T (Predicted Effect: Neutral; Score: -69; Expected Accuracy: 82\%) did not affect the protein structure (Figure 3). The results of Polyphen-2 analysis demonstared that the MTRR C524T mutation was a benign mutation in both HumVar and HumDiv models (score, 0.000; sensitivity: 1.00; specificity: 0.00) (Figure 4). Analysis of the MTRR secondary structure by various methods, including Chou-Fasman, GOR, and neural network showed that the C524T mutation altered the coil structure to strand structure in the GOR method (Figure 4). Data from the RNAsnp software showed that C524T polymorphism did not affect the MTRR mRNA structure $(\mathrm{PC} 524 \mathrm{~T}=0.8819)($ Table 5).

\section{Discussion}

Prostate cancer is considered as one of the prevalent male cancers, especially in developed countries (Wang et al., 2015). Different genetic, environmental, and social factors are associated with prostate cancer risk and mortality (Ruijter et al., 1999). Androgen receptor gene, AR, has an important role in the development and

Table 1. The Sequences of Primer and Condition of PCR

\begin{tabular}{|c|c|c|c|c|}
\hline SNP ID & Primer name & $5^{\prime}$ to $3^{\prime}$ oligonucleotide & PCR conditions & PCR prod. \\
\hline $\mathrm{A} 66 \mathrm{G}$ & MTRR1-f & 5'-GCAAAGGCCATCGCAGAAGACAT & $94^{\circ} \mathrm{C} 5^{\prime}, 94^{\circ} \mathrm{C}$ & $118 \mathrm{bp}$ \\
\hline (rs1801394) & MTRR1-r & 5'- AAACGGTAAAATCCACTGTAACGGC & $35^{\prime \prime}, 57^{\circ} \mathrm{C} 35^{\prime \prime}$ & \\
\hline C524T & MTRR2-f & 5'-TGGACAGACTGTCATTATCCTG & $72^{\circ} \mathrm{C} 45^{\prime \prime}, 35$ & $575 \mathrm{bp}$ \\
\hline (rs1532268) & MTRR2-r & 5'-GTTGTTTGATACCGAATGACCG & cycles, $72^{\circ} \mathrm{C} 5^{\prime}$ & \\
\hline
\end{tabular}

Table 2. Association Results of MTRR A66G with Prostate Cancer

\begin{tabular}{|c|c|c|c|c|c|}
\hline & \multicolumn{2}{|c|}{ No. and Percentage } & \multirow[t]{2}{*}{ OR $(95 \% \mathrm{CI})$} & \multirow[t]{2}{*}{$\chi^{2}$} & \multirow[t]{2}{*}{ P-value } \\
\hline & Control $(n=110)$ & Case $(n=108)$ & & & \\
\hline \multicolumn{6}{|l|}{ Genotype } \\
\hline AA & $40(36.36 \%)$ & $43(39.81 \%)$ & - & - & - \\
\hline AG & $49(44.55 \%)$ & $45(41.67 \%)$ & $0.85(0.47$ to 1.54$)$ & 0.273 & 0.6014 \\
\hline GG & $21(19.09 \%)$ & $20(18.5 \%)$ & $0.89(0.42$ to 1.87$)$ & 0.101 & 0.7512 \\
\hline $\mathrm{AG}+\mathrm{GG}$ & $70(63.64 \%)$ & $65(60.19 \%)$ & $0.86(0.50$ to 1.49$)$ & 0.275 & 0.5999 \\
\hline \multicolumn{6}{|l|}{ Allele } \\
\hline A & $129(58.64 \%)$ & $131(60.65 \%)$ & - & & - \\
\hline G & $91(41.36 \%)$ & $85(39.35 \%)$ & $0.92(0.63$ to 1.35$)$ & 0.183 & 0.6686 \\
\hline
\end{tabular}




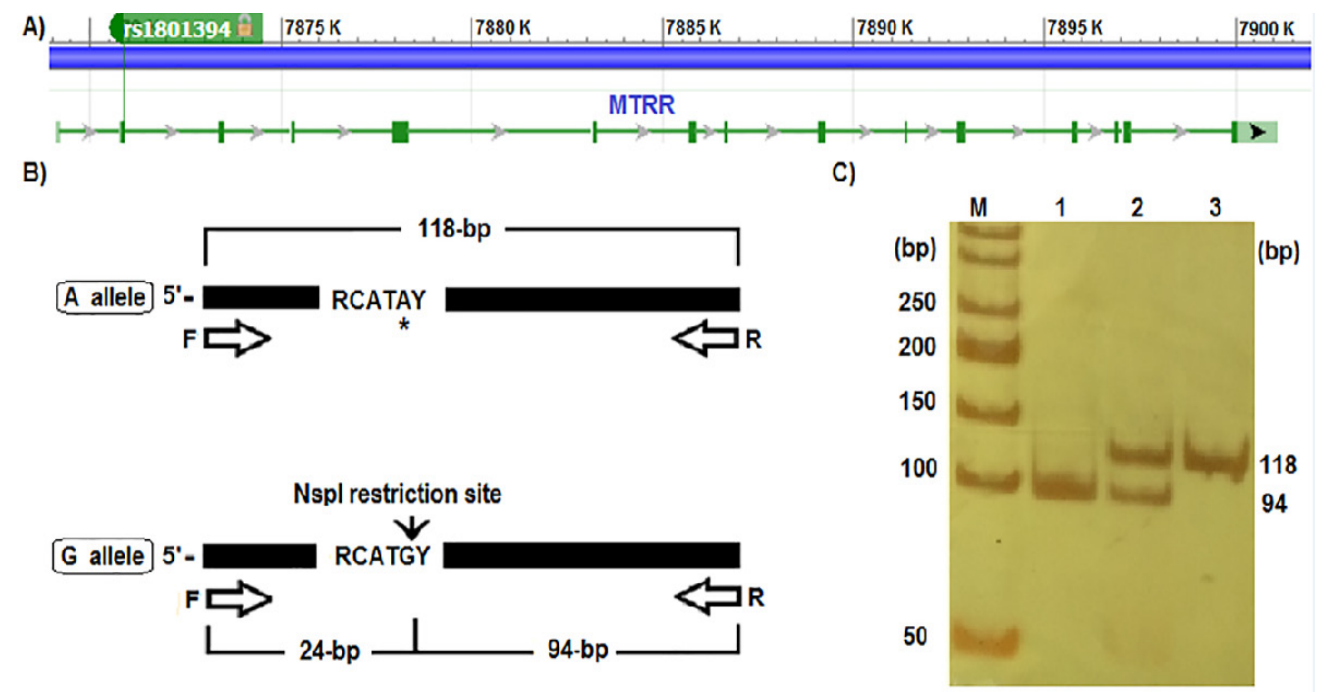

Figure 1. Polymorphism Analysis of A66G. MTRR gene map composed of 17 exons (A); Schematic digestion map of NspI (B). The PCR fragments which treated with NspI restriction endonuclease (M, DNA ladder; 1, genotype GG; 2 , genotype AG; 3, genotype AA) (C).

progression of prostate cancer (Xu et al., 2000). The FBP-5, DAN1, and RAB5A genes have special roles in cell proliferation in prostate cancer (Dhanasekaran et al., 2001). The MTRR gene can also increase the risk of prostate cancer. Methionine synthase reductase enzyme, encoded by the MTRR gene, is one of the key enzymes in folate cycle, playing an essential role in DNA making, repair, and methylation, as well as in methylation of histones and other proteins (Marchal et al., 2008). Therefore, any inappropriate changes in the

Table 3. Association Results of MTRR C524T with Prostate Cancer

\begin{tabular}{|c|c|c|c|c|c|}
\hline & \multicolumn{2}{|c|}{ No. and Percentage } & \multirow[t]{2}{*}{ OR $(95 \% \mathrm{CI})$} & \multirow[t]{2}{*}{$\chi^{2}$} & \multirow[t]{2}{*}{ P-value } \\
\hline & Control $(\mathrm{n}=110)$ & Case $(n=108)$ & & & \\
\hline \multicolumn{6}{|l|}{ Genotype } \\
\hline $\mathrm{CC}$ & $51(46.37 \%)$ & $35(32.41 \%)$ & - & & - \\
\hline $\mathrm{CT}$ & $41(37.27 \%)$ & $54(50.00 \%)$ & $1.92(1.06$ to 3.47$)$ & 4.707 & $0.0308^{*}$ \\
\hline TT & $18(16.36 \%)$ & $19(17.59 \%)$ & $1.54(0.71$ to 3.34$)$ & 1.192 & 0.2762 \\
\hline $\mathrm{CT}+\mathrm{TT}$ & $59(53.64 \%)$ & $73(67.59 \%)$ & $1.80(1.04$ to 3.13$)$ & 4.444 & $0.0358 *$ \\
\hline \multicolumn{6}{|l|}{ Allele } \\
\hline $\mathrm{C}$ & $143(65.00 \%)$ & $124(57.41 \%)$ & - & & - \\
\hline $\mathrm{T}$ & $77(35.00 \%)$ & $92(42.59 \%)$ & $1.38(0.94$ to 2.03$)$ & 2.647 & 0.1042 \\
\hline
\end{tabular}

OR, odds ratio; CI, confidence interval; The significant differences are displayed by*

A)

\begin{tabular}{|c|c|c|c|c|c|c|}
\hline $7870 \mathrm{~K}$ & $17875 \mathrm{~K}$ & 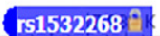 & $7885 \mathrm{~K}$ & $7890 \mathrm{~K}$ & $7895 \mathrm{~K}$ & $7900 \mathrm{~K}$ \\
\hline
\end{tabular}

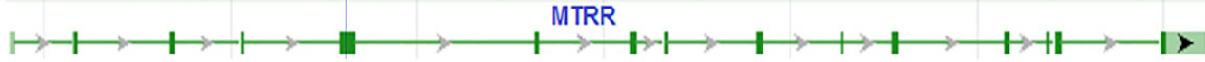

B)

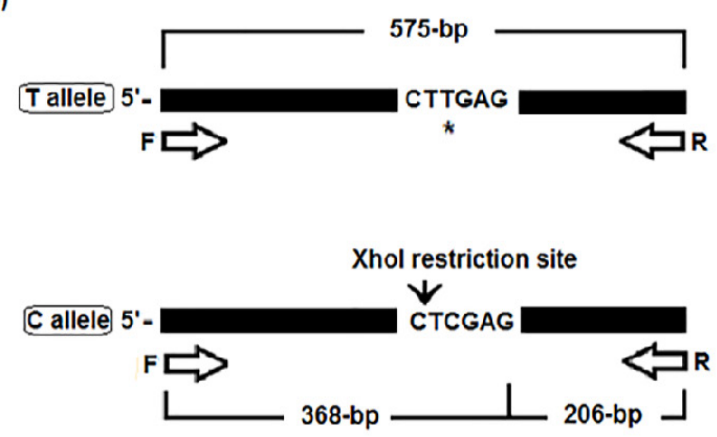

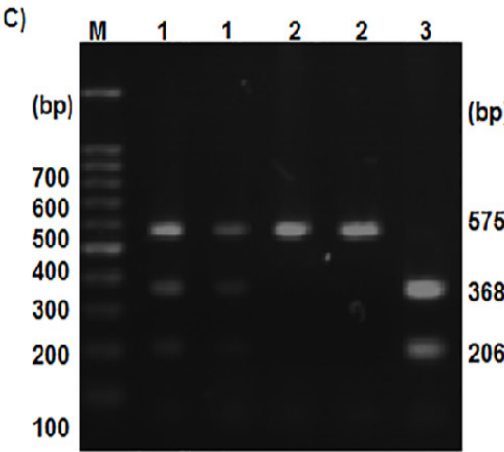

Figure 2. Polymorphism Analysis of C524T. MTRR gene map composed of 17 exons (A); Schematic digestion map of XhoI (B). The PCR fragments which treated with XhoI restriction endonuclease (M, DNA ladder; 1, genotype CT; 2 , genotype TT; 3 , genotype CC) (C). 


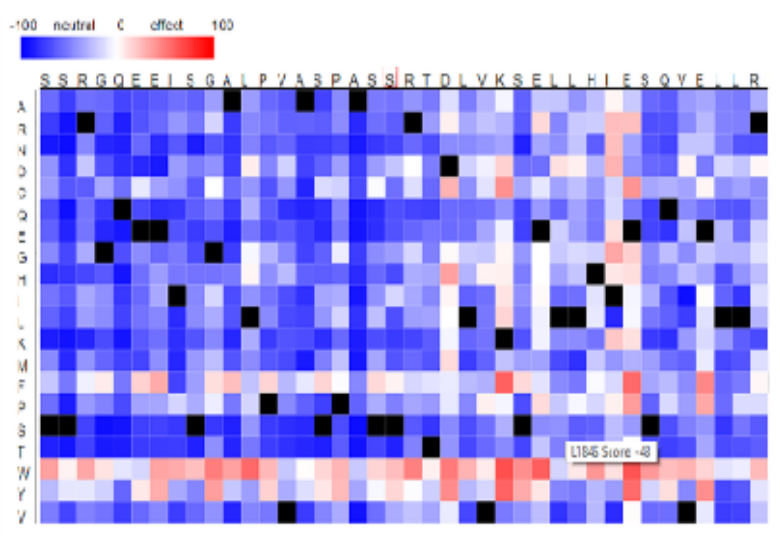

\begin{tabular}{|c|c|c|c|c|c|}
\hline Wilctypo Amins Moid of & Poecition & Vorient/Amino Aeis 4 & Predictos Ettreot o & Stome 4 & Exsoctod hosuracy $*$ \\
\hline$s$ & 175 & A & nesutral & .56 & $76 \%$ \\
\hline$s$ & 175 & R & noultal & 6 & $\operatorname{asc}$ \\
\hline$s$ & 175 & $\mathrm{~N}$ & nesutral & .73 & $87 \%$ \\
\hline$s$ & 175 & 0 & nouitral & -2 & $61 \%$ \\
\hline$s$ & 175 & $\mathrm{c}$ & neustral & .56 & $76 \%$ \\
\hline$s$ & 175 & a & noutral & 60 & $2: \omega$ \\
\hline 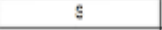 & 175 & $E$ & nestral & $\Leftrightarrow$ & $8 \% \%$ \\
\hline 8 & 178 & G & noutral & 30 & $65 \%$ \\
\hline 5 & 175 & $\mathrm{H}$ & nesutral & .71 & $87 \%$ \\
\hline$s$ & 175 & 1 & neutral & .15 & $57 \%$ \\
\hline 5 & 175 & $\square$ & nesitral & $-\infty$ & $8 \% \%$ \\
\hline $\mathrm{s}$ & 175 & k & neitral & $-\pi$ & $87 \%$ \\
\hline 5 & 175 & M & neutral & -67 & $82 \%$ \\
\hline 9 & 175 & $F$ & ofoct & 4 & $53 \%$ \\
\hline s & $1 / 0$ & r & กeutral & $-\infty$ & $12 \%$ \\
\hline$s$ & 175 & $\mathrm{~s}$ & neittal & 9 & $97 \%$ \\
\hline s & $1 / 2$ & 1 & nestral & औ & $90 \%$ \\
\hline$s$ & 175 & $\omega$ & aftart & $2 \pi$ & $\operatorname{ass} \%$ \\
\hline$s$ & $1 / 2$ & $\gamma$ & eted & 16 & $2 \%$ \\
\hline$s$ & 175 & $\mathrm{v}$ & neitral & $n$ & aAs \\
\hline
\end{tabular}

Figure 3. The Results of SNAP Server for Proteins with Phenotype 175L

structure of the MTRR gene can cause impaired regulation of methylation, leading to different cancers, namely prostate. Given that the MTRR rs1801394 and MTRR rs1532268 polymorphisms were introduced as common polymorphisms in previous studies (Zeng et al., 2011), this study was conducted on these two polymorphisms. The aim of the current study was to assess the association between prostate cancer and A66G and C524T SNPs in the MTRR genes.

Contradictory results reported by studies on the association between A66G and C524T SNPs of the MTRR genes and prostate cancer may be due to differences in racial, geographic, and epigenetics characteristics, or due to dietary factors. Molecular mechanisms involved in MTRR deficiency and the association between the MTRR and prostate cancer has not been clarified yet, but the possible reasons can be as follows: First, the MTRR plays a key role in the balance of intracellular concentrations of folate, methionine, and

Table 4. Physicochemical Properties of MTRR in Normal and 175L Phenotypes

\begin{tabular}{lccccc}
\hline $\begin{array}{l}\text { protein } \\
\text { phenotype }\end{array}$ & $\begin{array}{c}\text { molecular } \\
\text { weight }\end{array}$ & pI & $\begin{array}{c}\text { estimated } \\
\text { half-life }\end{array}$ & $\begin{array}{c}\text { instability } \\
\text { indices }\end{array}$ & $\begin{array}{c}\text { aliphatic } \\
\text { index }\end{array}$ \\
\hline Wild & 77673.77 & 6.04 & 30 hours & 52.89 & 94.58 \\
175L & 77717.88 & 6.04 & 30 hours & 52.33 & 94.58 \\
\hline
\end{tabular}

A)

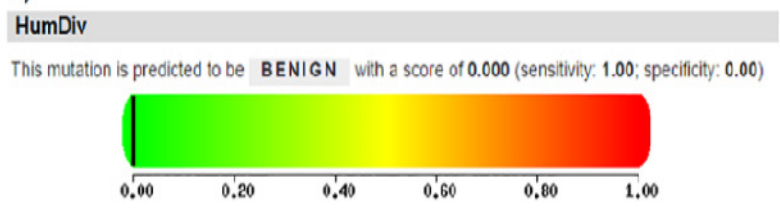

HumVar

This mutation is predicted to be BENIGN with a score of 0.000 (sensitivity. 1.00; specificity: 0.00 )

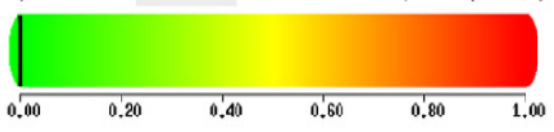

B)

AAseq. 121 RHFYDTGHADDCVGLELVVEPWIAGLWPALRKHFRSSR.GQEEISGALPVASPASSRTDLV CF C CCEECOHHHHEECCCEEEECEEECCHHHHHHICCCCCHHHICCCCCCCCOCCCOECCCOH

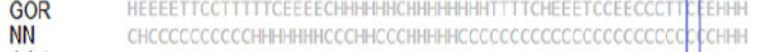
Joint CCEECCCCCCCCCCCCEEEECCCCCCCCHHHHHCCCCCCCCCCCCCCCCCCCCCCCCCCCHHH

AAseq. 121 RHFYDTGHADDCVGLELVWEPWIAGLWPALRKHFRSSRGQEEISGALPVASPASLRTDLV CF CCEECCHHHEECCCEEEECEEECCHHHHHHCCCCCHHHCCCCCCCCCCCCO GOR HEEEETTCCTTTITCEEEECHHHHHCHHHHHHHTTT THEEETCCCECCCT) EEHHH NN $\quad$ CHCCCCCCCCCCHHHHHHHCCCHHCCCHHHHHCCCCCCCCCCCCCCCCCCCCCOCF HHHH Joint CCEECCCCCCCCCCCCEEEECCCCCCCCOHHHHCCCCCCCCCCCCCCCCCCCCCCCCOCCCHHH

Figure 4. The Results of Polyphen-2 and Secondary Structure Analyses. Polyphen2 plot for proteins with 175L phenotype (A). Comparison of the MTRR normal protein secondary structure with $175 \mathrm{~L}$ mutant protein (B).

homocysteine. Second, methionine is an essential amino acid that provides a methyl group donor in methylation reactions (compared to S- adenosylmethionine). Third, it has been reported that the MTRR-66G phenotype, in comparison with the MTRR-66A phenotype, can decrease activity of enzyme (Matsuo et al., 2002). Consequently, decreased activity of MTRR enzyme leads to increase of homocysteine concentration and DNA hypermethylation. DNA hypermethylation reduces regulatory controls and can be considered as a carcinogen (Schalinske and Nieman, 2005). Imbalance in methylation of DNA (hypermethylation or hypomethylation) can cause MTRR deficiency and, consequently, leads to carcinogenesis (Fearon and Vogelstein, 1990; Issa et al., 1994).

Eukaryotic gene regulation is an intricate procedure. Initiation step in transcription process is a greatly precise and complex incident, during which cis-acting elements and trans-acting factors are involved. The trans-acting factors are considered as a substrate for cis-acting DNA sequences and through this way the DNA transcription launches. Elevated methylation rate in the promoter region results in decreased gene expression, while methylation of transcribed area has mutable influence on gene regulation (Jones, 1999). Some mechanisms are suggested for the repression of transcription through DNA methylation. According to one of these mechanisms, repression of transcription includes straight interposition with the interaction of particular transcription factors

Table 5. The Effect of C524T Polymorphism on the $M T R R$ mRNA Structure

\begin{tabular}{lcccc}
\hline SNP & Folding Window & Local region & distance & p-value \\
\hline C524T & $324-724$ & $483-556$ & 0.0051 & 0.8819 \\
\hline
\end{tabular}

Asian Pacific Journal of Cancer Prevention, Vol 201449 
to their promoter DNA-binding regions. Numerous transcription factors containing E2F, AP-2, and NFkB, diagnose DNA sequences comprising $\mathrm{CpG}$ dinucleotides, and interaction of these factor has been reported to be blocked by $\mathrm{CpG}$ methylation. The other mechanism of suppression of transcription is straight interaction of particular transcription repressors with methylated $\mathrm{CpG}$ (Tate and Bird, 1993). Additionally, methylation of DNA can influence modifications of histone and structure of chromatin, leading to gene regulation change (Bender et al., 1998).

Different patterns of DNA methylation are found in prostatic cancer (Majumdar et al., 2011). In addition, hypermethylation of the $\mathrm{CpG}$ islands in promoter region of tumor suppressor genes may be the most current change in cells of prostatic carcinoma which can be associated with tumorigenesis of prostate (Lin and WG, 2003). Folate metabolism is an elementary cellular pathway that may impact procedures such as methylation of DNA, and the MTRR is an important regulatory enzyme of this pathway. Thus, any alterations in the structure and/or expression of the MTRR can affect the process of DNA methylation and induce carcinogenesis.

The role of nutrients in gene regulation via interaction with genetic variation and modification of genome methylation has recently got extensive consideration. The homeostasis disturbance in the folate (one-carbon) metabolism increases the risk of neural tube defects, cardiovascular disease, and all cancers. Insufficiencies of the two crucial micronutrients in folate metabolism, including cobalamin and folate could result in homeostasis disturbance (Ebbing et al., 2009).

Amino acids alteration caused by genetic polymorphisms can leads to change in other parameters such as secondary structure and hydrophobicity (Raygan et al., 2016; Zamani-Badi et al., 2017; Mazheri et al., 2017; Zamani-Badi et al., 2018a; Nejati et al., 2018; Tameh et al., 2018). Genetic polymorphisms may also affect mRNA structure. The mentioned changes are evaluated by bioinformatics tools. Some previous reports revealed that bioinformatics was an effective device to assess molecular biology and specially to examine the molecular effects of gene polymorphisms (Jamali et al., 2016; Soleimani et al., 2017; Zamni-Badi et al., 2018b; Teimouri et al., 2018; Mobasseri et al., 2019). Therefore, in silico tools were employed in this study to evaluate the effects of C524T polymorphisms on the MTRR molecular aspects.

One of the limitations of our study was non-consideration of the interaction between these genes and other genes, or between these genes and environmental factors since the possible interactions between gene-gene and geneenvironment are effective in most cellular activities. Another limitation of the present study was non-provision of data on homocysteine and folate status for the cases and control groups.

In a nutshell, we found that the MTRR C524T was a risk factor for prostate cancer; therefore, determining the genotype of the MTRR-C524T SNP can be useful as a molecular marker to screen susceptible individuals for prostate cancer. However, we did not find the MTRR-A66G SNP as a suitable biomarker for prostate cancer. Further studies with larger sample sizes are required to reach more reliable results.

\section{Declaration}

The author reports no financial or commercial conflicts of interest.

\section{References}

Bender CM, Zingg JM, Jones PA (1998). DNA methylation as a target for drug design. Pharm Res, 15, 175-87.

Danasekaran SM, Barrette TR, Ghosh D (2001). Delineation of prognostic biomarkers in prostate cancer metastasis. Nature, 412, 822-6.

Donnelly JG (2001). Folic acid. Crit Rev Clin Lab Sci, 38, 183- 223.

Duthie SJ, Hawdon A (1998). DNA instability (strand breakage, uracil misincorporation, and defective repair) is increased by folic acid depletion in human lymphocytes in vitro. FASEB J, 12, 1491-7.

Duthie SJ, Narayanan S, Blum S, Pirie L, Brand GM (2000). Folate deficiency in vitro induces uracil misincorporation and DNA hypomethylation and inhibits DNA excision repair in immortalized normal human colon epithelial cells. Nutr Cancer, 37, 245-51.

Ebbing M, Bønaa KH, Nygård O, et al (2009). Cancer incidence and mortality after treatment with folic acid and vitamin B12. $J A M A, \mathbf{3 0 2}, 2119-26$.

Ebrahimi A, Colagar AH, Karimian M (2017). Association of human methionine synthase-A2756G transition with prostate cancer: A case-control study and in Silico analysis. Acta Med Iran, 55, 297-303.

Fearon ER, Vogelstein B (1990). A genetic model for colorectal tumorigenesis. Cell, 61, 759-67.

Fowler B (2005). Homocysteine: overview of biochemistry, molecular biology, and role in disease processes. Semin Vasc Med, 5, 77-86.

Godmann M, Lambrot R, Kimmins S (2009). The dynamic epigenetic program in male germ cells: Its role in spermatogenesis, testis cancer, and its response to the environment. Microsc Res Tech, 72, 603-19.

Issa JP, Ottaviano YL, Celano P, et al (1994). Methylation of the oestrogen receptor $\mathrm{CpG}$ island links ageing and neoplasia in human colon. Nat Genet, 7, 536-40.

Jamali S, Karimian M, Nikzad H, Aftabi Y (2016). The c.-190 $\mathrm{C}>\mathrm{A}$ transversion in promoter region of protaminel gene as a genetic risk factor for idiopathic oligozoospermia. $\mathrm{Mol}$ Biol Rep, 43, 795-802.

Jemal A, Bray F, Center MM, et al (2011). Global cancer statistics. CA Cancer J Clin, 61, 69-90.

Jones PA (1999). The DNA methylation paradox. Trends Genet, 15, 34-7.

Karimian M, Colagar AH (2016). Association of C677T transition of the human methylenetetrahydrofolate reductase (MTHFR) gene with male infertility. Reprod Fertil Dev, 28, 785-94.

Karimian M, Colagar AH (2016). Methionine synthase A2756G transition might be a risk factor for male infertility: Evidences from seven case-control studies. Mol Cell Endocrinol, 425, 1-10.

Karimian M, Hosseinzadeh Colagar A (2018). Human MTHFRG1793A transition may be a protective mutation against male infertility: a genetic association study and in silico analysis. Human Fertility. Hum Fertil (Camb), 21, 128-36.

Karimian M, Aftabi Y, Mazoochi T, et al (2018). Survivin polymorphisms and susceptibility to prostate cancer: a 
genetic association study and an in silico analysis. Excli $J$, 17, 479-91.

Kim KC, Friso S, Choi SW (2009). DNA methylation, an epigenetic mechanism connecting folate to healthy embryonic development and aging. J Nutr Biochem, 20, 917-26.

Le Leu RK, Young GP, McIntosh GH (2000). Folate deficiency diminishes the occurrence of aberrant crypt foci in the rat colon but does not alter global DNA methylation status. J Gastroenterol Hepatol, 15, 1158-64.

Lin X, Nelson WG (2003). Methyl-CpG-binding domain protein-2 mediates transcriptional repression associated with hypermethylated GSTP1 CpG islands in MCF-7 breast cancer cells. Cancer Res, 63, 498-504.

Majumdar S, Buckles E, Estrada J, Koochekpour S (2011). Aberrant DNA methylation and prostate cancer. Curr Genomics, 12, 486-505.

Marchal C, Redondo M, Reyes-Engel A, et al (2008). Association between polymorphisms of folate-metabolizing enzymes and risk of prostate cancer. Eur J Surg Oncol, 34, 805-10.

Mazaheri M, Karimian M, Behjati M, Raygan F, Colagar AH (2017). Association analysis of rs 1049255 and rs4673 transitions in $\mathrm{p} 22$ phox gene with coronary artery disease: A case-control study and a computational analysis. Ir J Med Sci, 186, 921-28.

Mazoochi T, Karimian M, Ehteram H, Karimian A (2019). Survivin c.-31G $>$ C (rs9904341) gene transversion and urinary system cancers risk: a systematic review and a meta-analysis. Per Med, 16, 67-78.

Mobasseri N, Nikzad H, Karimian M (2019) Protective effect of estrogen receptor $\alpha$-PvuII transition against idiopathic male infertility: A case-control study and meta-analysis. Reprod Biomed Online, Doi: 10.1016/j.rbmo.2019.01.008.

Muslumanoglu MH, Tepeli E, Demir S, et al (2009). The analysis of the relationship between A1298C and C677T polymorphisms of the MTHFR gene with prostate cancer in Eskisehir population. Genet Test Mol Biomarkers, 13, 641-5.

Nejati M, Atlasi MA, Karimian M, Nikzad H, Azami Tameh A (2018). Lipoprotein lipase gene polymorphisms as risk factors for stroke: a computational and meta-analysis. Iran J Basic Med Sci, 21, 701-8.

Nikzad H, Karimian M, Sareban K, Khoshsokhan M, Colagar AH (2015). MTHFR-Ala222Val and male infertility: a study in Iranian men, an updated meta-analysis and an in silico-analysis. Reprod Biomed Online, 31, 668-80.

Noureddini M, Mobasseri N, Karimian M, Behjati M, Nikzad H (2018). Arg399Gln substitution in XRCC1 as a prognostic and predictive biomarker for prostate cancer: evidence from 8662 subjects and a structural analysis. J Gene Med, 20, e3053.

Olteanu H, Banerjee R (2001). Human methionine synthase reductase, a soluble $\mathrm{P}-450$ reductase-like dual flavoprotein, is sufficient for NADPH-dependent methionine synthase activation. $J$ Biol Chem, 276, 35558-63.

Rafatmanesh A, Nikzad H, Ebrahimi A, Karimian M, Zamani $\mathrm{T}$ (2018). Association of the c. $-9 \mathrm{C}>\mathrm{T}$ and c.368A $>\mathrm{G}$ transitions in H2BFWT gene with male infertility in an Iranian population. Andrologia, 50, e12805.

Rai V, Yadav U, Kumar P (2012). MTRR A66G polymorphism among two caste groups of Uttar Pradesh (India). Indian $J$ Med Sci, 66, 136-40.

Ruijter E, van de Kaa C, Miller G, et al (1999). Molecular genetics and epidemiology of prostate carcinoma. Endocr Rev, 20, 22-45.

Schalinske KL, Nieman KM (2005). Disruption of methyl group metabolism by ethanol. Nutr Rev, 63, 387-91.

Silaste ML, Rantala M, Sämpi M, et al (2001). Polymorphisms of key enzymes in homocysteine metabolism affect diet responsiveness of plasma homocysteine in healthy women. J Nutr, 131, 2643-7.

Soleimani Z, Kheirkhah D, Sharif MR, et al (2017). Association of CCND1 Gene c. 870G> A Polymorphism with Breast Cancer Risk: A Case-ControlStudy and a Meta-Analysis. Pathol Oncol Res, 23, 621-31.

Suzuki T, Matsuo K, Hirose K, et al (2008). One-carbon metabolism-related gene polymorphisms and risk of breast cancer. Carcinogenesis, 29, 356-62.

Talebi E, Karimian M, Nikzad H (2018). Association of sperm mitochondrial DNA deletions with male infertility in an Iranian population. Mitochondrial DNA A DNA Mapp Seq Anal, 29, 615-23.

Tameh AA, Karimian M, Zare-Dehghanani Z, Aftabi Y, Beyer C (2018). Role of steroid therapy after ischemic stroke by n-methyl-d-aspartate receptor gene regulation. J Stroke Cerebrovasc Dis, 27, 3066-75.

Tate PH, Bird AP (1993). Effects of DNA methylation on DNA-binding proteins and gene expression. Curr Opin Genet Dev, 3, 226-31.

Teimouri M, Najaran H, Hosseinzadeh A, Mazoochi T (2018). Association between two common transitions of $\mathrm{H} 2 \mathrm{BFWT}$ gene and male infertility: a case-control, meta, and structural analysis. Andrology, 6, 306-16.

Ulrich CM, Potter JD (2006). Folate supplementation: too much of a good thing?. Cancer Epidemiol Biomarkers Prev, 15, 189-93.

Ulrich CM, Potter JD (2007). Folate and cancer: timing is everything. JAMA, 297, 2408-9.

Wang D, Nguyen MM, Masoodi KZ, et al (2015). Splicing factor Prp8 interacts with NESAR and regulates androgen receptor in prostate cancer cells. Mol Endocrinol, 29, 1731-42.

$\mathrm{Xu} \mathrm{J}$ (2000). International consortium for prostate cancer genetics. Combined analysis of hereditary prostate cancer linkage to 1q24-25: results from 772 hereditary prostate cancer families from the international consortium for prostate cancer genetics. Am J Hum Genet, 66, 945-57.

Zamani-Badi T, Nikzad H, Karimian M (2018a). IL-1R AVNTR and IL-1 $\alpha 4845 \mathrm{G}>\mathrm{T}$ polymorphisms and risk of idiopathic male infertility in Iranian men: A case-control study and an in silico analysis. Andrologia, 50, e13081.

Zamani-Badi T, Karimian M, Azami Tameh A, Nikzad H (2018b). IL-1 $\alpha$ C376A transversion and risk of idiopathic male infertility in Iranian men: a genetic association study. Int J Fertil Steril, 12, 229-34.

Zamani-Badi T, Karimian M, Azami-Tameh A, Nikzad H (2017). Association of C3953T transition in interleukin $1 \beta$ gene with idiopathic male infertility in an Iranian population. Hum Fertil (Camb), doi: 10.1080/14647273.2017, 1-7.

Zeng W, Liu L, Tong Y, et al (2011). A66G and C524T polymorphisms of the methionine synthase reductase gene are associated with congenital heart defects in the Chinese Han population. Genet Mol Res, 10, 2597-605.

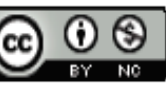

This work is licensed under a Creative Commons AttributionNon Commercial 4.0 International License. 